\title{
METABOLIC SYNDROME IN RHEUMATOID ARTHRITIS
}

\author{
Manka V, Galajda P, Sagova I, Klimentova A, Kantarova D, \\ Stancik M, Mokan M.
}

$1^{\text {st }}$ Clinic of Internal Medicine, Jessenius Faculty of Medicine, Comenius University and University Hospital in Martin, Slovakia

A bs tract

Inflammation is a key component of obesity and type 2 diabetes mellitus also as risk factors of cardiovascular disease. Patients with chronic inflammatory diseases such as rheumatoid arthritis or systemic lupus erythematosus have an increased risk of cardiovascular diseases. The expected higher prevalence of metabolic syndrome and its components in rheumatic diseases (such as possible cause of increased cardiovascular risk) was confirmed in rheumatoid arthritis, systemic lupus, ankylosing spondylitis and psoriatic arthritis.

The aim of our study was to assess the relationship of rheumatoid arthritis to increased cardiovascular risk in the presence of risk factors involved in complex of metabolic syndrome, including prediabetic state, central obesity, atherogenic dyslipidemia, and hypertension. In the sample of patients with rheumatoid arthritis, the prevalence of the metabolic syndrome according to IDF, AHA/NHLBI and also NCEP ATPIII criteria compared with the Slovak population in all age groups is higher. In patients older than 60 years according to IDF criteria was more than $55 \%$. Patients treated with methotrexate had the lowest prevalence of metabolic syndrome, even lower than the control population. The most frequented component of the metabolic syndrome was obesity (whether in the evaluation of waist circumference or BMI). Also, patients with higher inflammatory activity (evaluated by CRP) had a higher prevalence of metabolic syndrome.

Key words: metabolic syndrome, insulin resistance, cardiovascular risk, inflammatory connective tissue disease

\section{INTRODUCTION}

As in other sciences as well in medicine the progress for many centuries was do to accidental discoveries. Only with the birth of rationalism human effort begins slowly to turn on long-term focused research. One example is the work of the American endocrinologist Gerald Reaven, who researched diabetes and insulin resistance since 1968. Twenty years after he presented the revolutionary theory of link between central obesity, diabetes and hypertension as a sequel of insulin resistance or impaired glucose tolerance (1).

Other scientists soon discovered the relationship of metabolic syndrome to other pathological entities including inflammatory connective tissue diseases $(2,3,4,5,6,7,8,9)$. They also found that despite the absence of traditional risk factors, the prevalence of the metabolic syndrome in some diseases is higher $(7,10)$. Currently, scientists directed effort to fully understand the etiopathogenetic processes common to both humoral and cellular level.

Definition of metabolic syndrome has undergone quite a long way. There is a longstanding effort by the most accurate quantitative criteria select from a population people with the metabolic syndrome and then stratified them according to risk level. In this sense, nearly every new definition tightens the criteria for metabolic syndrome (MS) and thus increases the prevalence of metabolic syndrome in the population, although at the cost of a reduction in the prediction of cardiovascular risk.

The aim of this study was to assess the relationship of selected inflammatory diseases of connective tissue to increased cardiovascular risk in the presence of risk factors involved in a complex of the metabolic syndrome, including prediabetic state, central obesity, atherogenic dyslipidemia, and hypertension. Given the prevalence of connective tissue diseases, we chose to study patients with rheumatoid arthritis.

Address for correspondence:

Viliam Manka, MD,PhD, $1^{\text {st }}$ Clinic of Internal Medicine, JFM CU and UHM, Kollarova 2, 03601 Martin, Slovakia Phone: + 42190228304; e-mail: vilcoo@gmail.com 
The specific study objectives were:

1. analyze the file in terms of demographic data, available case history data, obtained clinical and laboratory parameters,

2. evaluate the prevalence of MS according to NCEP ATPIII, AHA/NHLBI and the IDF criteria in patients with rheumatoid arthritis (RA), including age groups, compare with the prevalence in control group - Slovak population,

3. determine the prevalence of components of MS, their average values and compare them with the Slovak population,

4. compare the prevalence of MS in relation to the inflammatory activity, compare the prevalence of components of MS in groups with normal and high inflammatory activity,

5. compare the prevalence of MS in groups of RA patients with various types of drugs (classic DMARDS, modern immunosuppresive drugs), also examine the possible impact of treatment with glucocorticoids (GC),

6. express the prevalence of components of MS in patients with RA treated with methotrexate, compare with the rest.

\section{METHODS}

In the clinical study there were examined 87 patients with rheumatoid arthritis over 18 years of life. To avoid seasonal effects, all patients were examined in the third quarters of 2009 to 2011. All patients met the following criteria: history of RA according to criteria of American College of Rheumatology (of 1987, new of 2011), age over 18 years, signed informed consent, this corresponds to a random sample of treated or monitored adult patients with RA. The examined patients were 4 men (4.6\%) and 83 women (95.4\%). Basic demographic data were obtained from case sheets.

In the age group 30-39 years were examined two women, in the age group 40-49 years 13 women, in the age group 50-59 years one man and 33 women, and finally in the age group above 60 years 3 men and 35 women. The mean age was $58.8 \pm 9.4$ years, median 58 years. The average age for men was $65.2 \pm 9.2$ years, median 65.5 years. The average age of women was $58.5 \pm 9.3$ years, median 58 years.

In each patient a questionnaire was carried out assessing the presence of selected components of the metabolic syndrome and its treatment (hypertension, diabetes mellitus, dyslipidemia). To obtain other selected parameters such as length of treatment of rheumatic diseases and risk factors outpatient medical records were used.

Before the rheumatologic examination fasting blood test was performed to determine serum levels of C-reactive protein (CRP), rheumatoid factor (RF), glucose, lipidogram - levels of triglycerides (TG), HDL and LDL cholesterol. To assess the presence of metabolic syndrome anthropometric measurements (height, weight, calculating BMI, waist circumference in $\mathrm{cm}$, blood pressure) were also carried out. The presence of metabolic syndrome was determined based on the NCEP ATPIII, AHA / NHLBI and IDF criteria.

As a control group in the assessment of the prevalence of MS we used subjects in the project Prevalence of diabetes mellitus and metabolic syndrome in Slovakia (2) (3).

To evaluate the results, we used standard statistical methods. The prevalence was expressed as a percentage, mean values were calculated using the arithmetic mean and median. Variability is expressed as arithmetic mean \pm standard deviation (SD).

In comparison of individual groups or comparison of the parameters we used the unpaired Student's t-test and Pearson's chi-square test. The limit of statistical significance were determined by the value of $\alpha=0.01$. The $p$-value $<0.01$ was accepted alternative hypothesis and the difference between the data we considered nonrandom. In determining the correlation relationships, we used Pearson correlation coefficient. 


\section{RESULTS}

\section{Prevalence of metabolic syndrome in patients with rheumatoid arthritis}

The prevalence of MS in patients with RA according to the NCEP ATPIII criteria was $44.8 \%, 47.1 \%$ according to AHA/NHLBI criteria and $48.3 \%$ by IDF criteria (Table 1 ).

Table 1 Prevalence of metabolic syndrome in patients with rheumatoid arthritis in different age groups according to NCEP ATPIII, AHA/NHLBI and IDF criteria $(n=87)$

\begin{tabular}{|l|c|c|c|}
\hline & $\begin{array}{c}40-49 \text { years } \\
\mathrm{n}=13\end{array}$ & $\begin{array}{c}50-59 \text { years } \\
\mathrm{n}=34\end{array}$ & $\begin{array}{c}>60 \text { years } \\
\mathrm{n}=38\end{array}$ \\
\hline NCEP ATPIII & $38.4 \%$ & $38.2 \%$ & $52.6 \%$ \\
\hline AHA/NHLBI & $38.4 \%$ & $44.1 \%$ & $52.6 \%$ \\
\hline IDF & $46.1 \%$ & $41.1 \%$ & $55.2 \%$ \\
\hline
\end{tabular}

All results are significantly higher than in the control group - the Slovak population (p $<0.01$ ). To some extent this is due to different age structure of the compared groups. Taking into account the age in different age groups, the difference in the prevalence of MS is lower, but still statistically significant ( $\mathrm{p}<0.01$ ).

\section{Prevalence of components of metabolic syndrome}

The individual components of MS are most often represented by the parameters of central obesity - waist circumference (whether by NCEP ATPIII criteria or AHA/NHLBI and IDF criteria) up to $73.6 \%$ respectively $86.2 \%$ of patients. The second most common component of MS was elevated blood pressure in $55.2 \%$. Followed by metabolic components such as increased levels of TAG (43.7\%), low HDL (33.3\%) and hyperglycemia (Fig. 1).

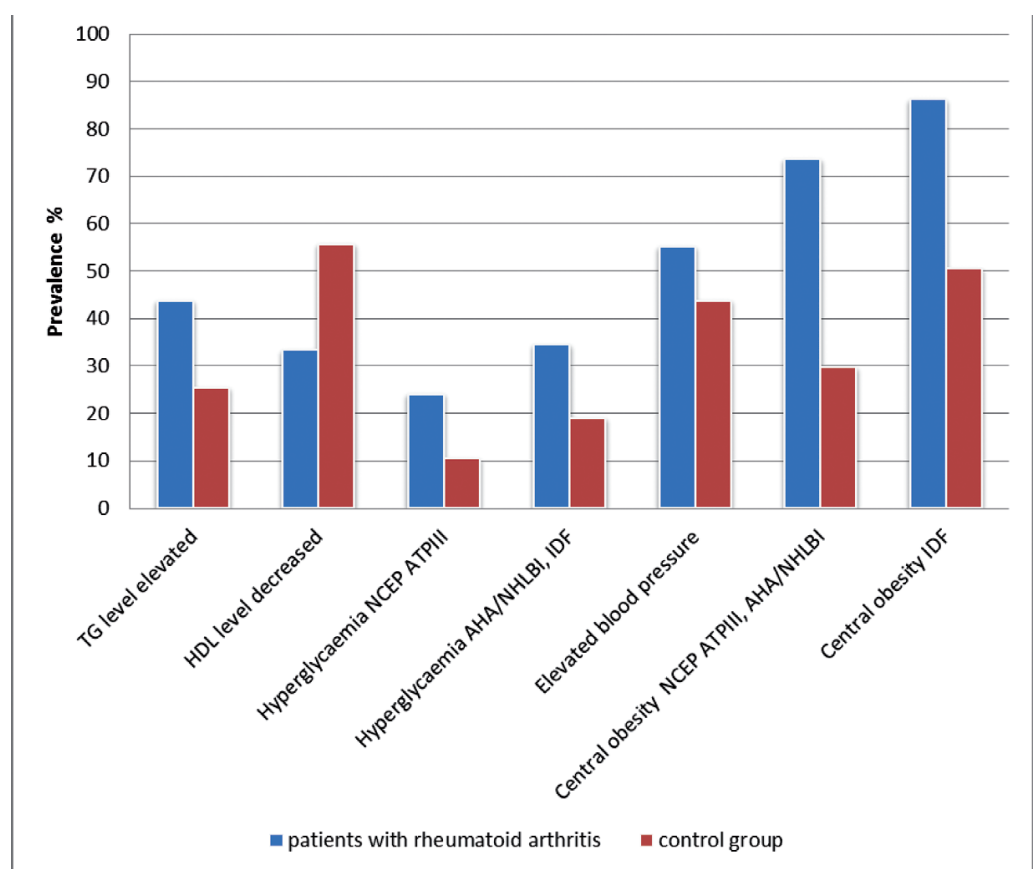

Fig. 1 Prevalence of individual components of metabolic syndrome according to NCEP ATPIII, AHA/NHLBI and IDF criteria in patients with rheumatoid arthritis and in the control group $(\mathrm{n}=1604)$ 
As in the control group and the parameters of overall and central obesity is closely correlated $(\mathrm{r}=0.91, \mathrm{p}<0.01)$. Obese $(\mathrm{BMI}>30)$ patients were $35.6 \%, 78.2 \%$ patients were overweight (BMI> 25).

\section{Prevalence of metabolic syndrome components, depending on age}

Prevalence of metabolic syndrome components in the age group 40-49 years:

In the age group 40-49 years is the representation of individual components of MS in patients with RA compared with the control group more frequently $(p<0.01)$ except the prevalence of elevated blood pressure, which is in patients with RA less than one third $(p<0,01)$

Prevalence of metabolic syndrome components in the age group 50-59 years:

In the age decade from 50 to 59 years the prevalence of individual components of MS in patients with RA (with adequate increase) is similar to the control group ( $\mathrm{p}<0.01$ ). Also there is a paradox from the previous decade, where the prevalence of elevated blood pressure in patients with RA is lower ( $\mathrm{p}<0.01)$. The second paradox is significantly lower prevalence of low HDL levels in patients with RA ( $\mathrm{p}<0.01)$.

Prevalence of metabolic syndrome components in the age group over 60 years:

In the age group above 60 years the individual components of MS in patients with RA is comparable to the previous decade. There remains a paradox of a lower prevalence of elevated blood pressure in patients with RA and also the paradox of significantly lower prevalence of low HDL levels in patients with RA ( $p<0.01)$. Interesting is a significant increase in the prevalence of hyperglycemia - which is almost twice higher $(p<0.01)$.

\section{Effect of inflammatory activity on the prevalence of metabolic syndrome}

We compared two groups of patients, one group with normal inflammatory activity characterized by level of CRP $<5 \mathrm{mg} / 1$ and a second group with increased inflammatory activity characterized by level of CRP $5 \mathrm{mg} / 1$ and more. The average age of patients was comparable in both groups (58.8 and 60.1 years). We confirmed the assumption - patients with increased inflammatory activity have a higher prevalence of metabolic syndrome according to NCEP ATPIII, AHA/NHLBI and IDF criteria ( $<<0.01$ ) (Table 2).

Table 2 Comparison of the prevalence of metabolic syndrome in patients with rheumatoid arthritis according to inflammatory activity

\begin{tabular}{|c|c|c|c|}
\hline & NCEP ATPIII & AHA/NHLBI & IDF \\
\hline $\begin{array}{c}\text { CRP }<5 \mathrm{mg} / 1 \\
\mathbf{n}=55\end{array}$ & $40.0 \%$ & $41.8 \%$ & $41.8 \%$ \\
\hline $\begin{array}{c}\mathrm{CRP}>5 \mathrm{mg} / 1 \\
\mathbf{n}=\mathbf{3 2}\end{array}$ & $47.8 \%$ & $52.2 \%$ & $56.5 \%$ \\
\hline $\mathbf{p}$ & $<0.01$ & $<0.01$ & $<0.01$ \\
\hline
\end{tabular}

Almost all components of the metabolic syndrome were higher in patients with higher inflammatory activity, except the prevalence of low HDL (30.9\% versus $31.8 \%$ ).

\section{Effect of treatment on the prevalence of metabolic syndrome}

Most studied patients with RA were treated with methotrexate ( $\mathrm{n}=28 ; 33 \%$ ), the second most numerous group of patients was treated with coloid gold $(\mathrm{n}=15 ; 18 \%), 16 \%(\mathrm{n}=14)$ with sulfasalazine, $12 \%(n=10)$ with antimalarials, less than $10 \%$ of patients were treated with leflunomide or any other drug, and finally - 7\% of patients were not on the basal treatment. 
Prevalence of metabolic syndrome was low in patients treated with modern aggressive treatment such as methotrexate or leflunomide. In patients treated with methotrexate was even significantly lower than the same age group in the Slovak population ( $\mathrm{p}<0.01)$. The average age in each group was comparable (Fig. 2).

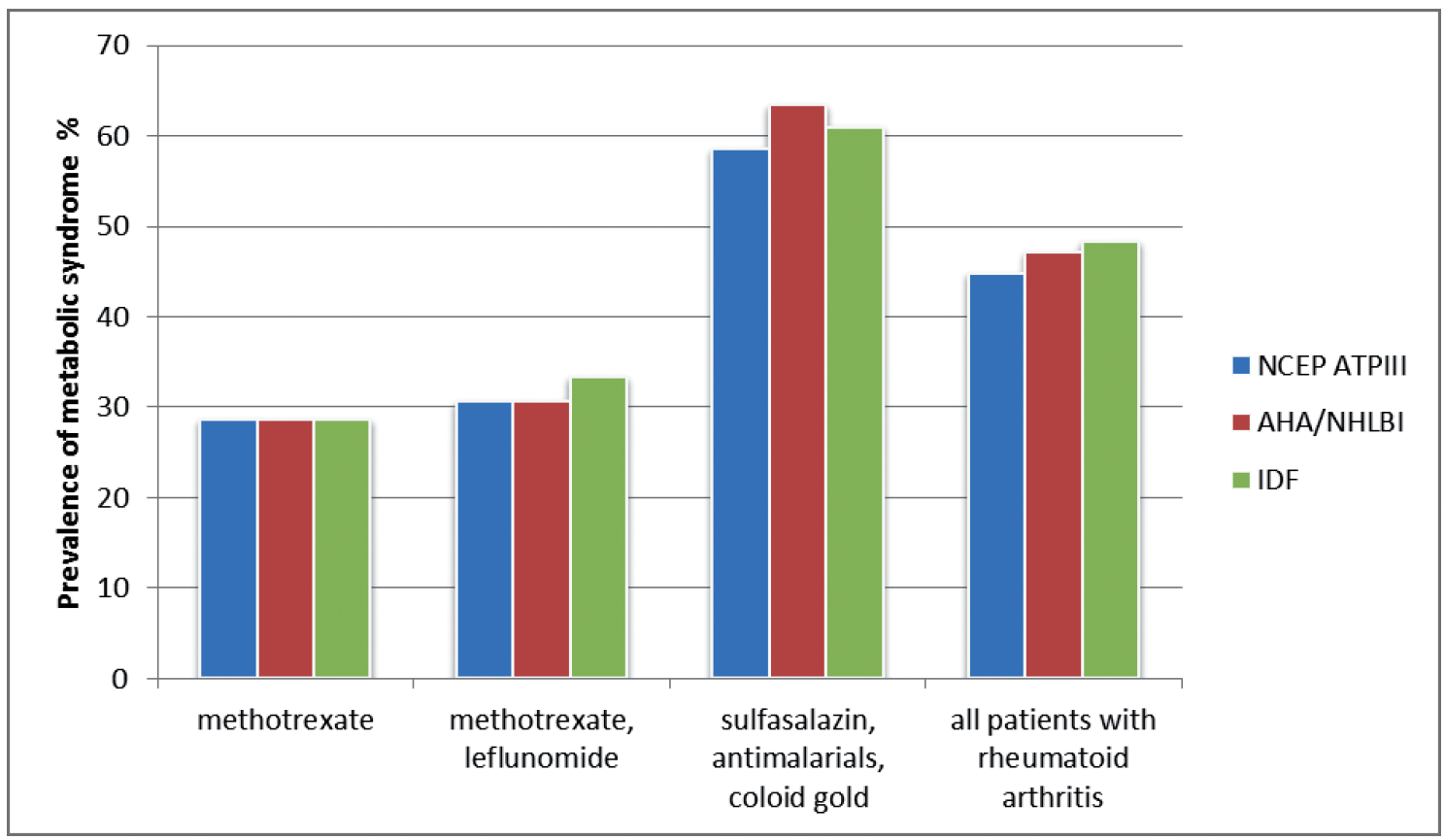

Fig. 2 The modifying effect of treatment on the prevalence of metabolic syndrome in patients with rheumatoid arthritis $(n=87)$

\section{Effect of corticosteroids on the prevalence of metabolic syndrome}

$30 \%$ of all patients were receiving combination therapy with GC. Generally, we assume that the GC side effects which increase weight will increase the prevalence of MS, on the other hand, immunosuppressive effect of the GC should improve the metabolic parameters and thus reduce prevalence of MS.

Given the number of patients in each group, we divided and examined the prevalence of MS in four groups - those taking GC, those not taking GC patients, patients receiving methotrexate in combination with GC and patients receiving methotrexate alone (without GC). Mean age was comparable in all groups.

When comparing all patients, patients treated by GC had a lower prevalence of MS (NCEP ATPIII criteria $-38.5 \%$ versus $47.5 \%, \mathrm{p}<0.01$ ). In assessing the prevalence in patients treated with methotrexate - patients treated with combination of methotrexate and GC had prevalence of MS significantly higher than patients treated with monotherapy (NCEP ATPIII criteria - $33.3 \%$ versus $25 \%$, $\mathrm{p}<0.01$ ) (Fig. 3).

\section{Effect of methotrexate therapy on the prevalence of metabolic syndrome}

We also examined by which parameters of MS methotrexate treatment positively or negatively affects the prevalence of MS.

The average age in the methotrexate group (58.2 years) were comparable with the average age of all patients (58.8 years). Patients treated with methotrexate have significantly lower prevalence of metabolic components such as lipids, or glycemia, differences in the preva- 


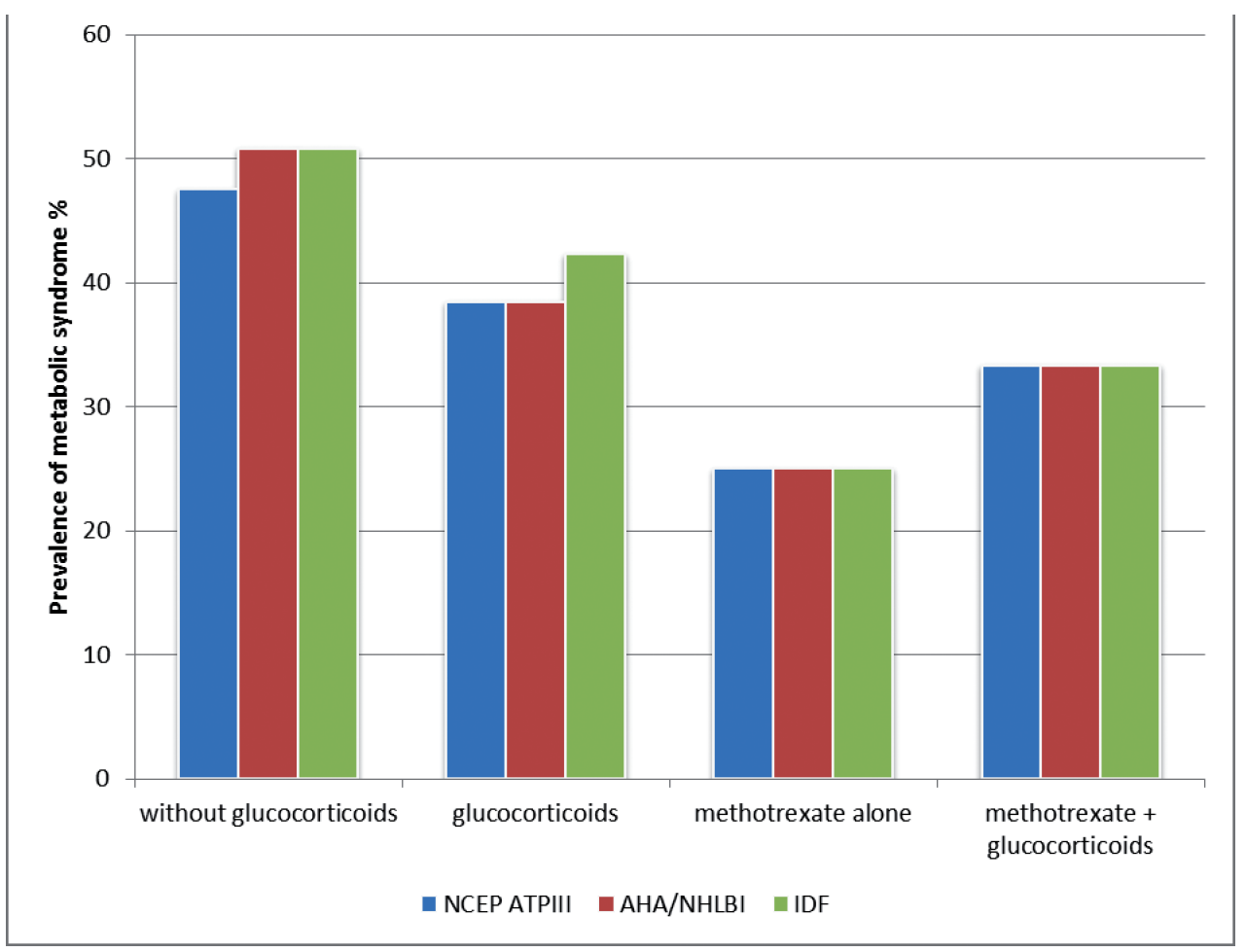

Fig. 3 Comparison of the prevalence of metabolic syndrome in patients with rheumatoid arthritis: modifying effect of treatment with corticosteroids $(n=87)$

lence of elevated blood pressure $(p=0.75)$ or in the prevalence of central obesity $(p=0.92)$ were not significant.

\section{DISCUSSION}

The prevalence of MS in patients with RA was significantly higher than in the control population (according to NCEP ATPIII 44.8\% in RA versus 20.1\% in control population examined in the project of Prevalence of metabolic syndrome in Slovakia). Adjusted for age and divided into age groups, the prevalence MS patients with RA in each age group are still significantly higher. Similar results of higher prevalence of MS according to various criteria in patients with RA and with other rheumatic diseases published also other authors (2) (4) (5) (6) (11) (7) (9) (8) (3).

If we compare the prevalence of MS in patients with RA according to various criteria, the differences are not as strong as when using different criteria in the control group (prevalence of MS in the Slovak population according to NCEP ATPIII 20.1\%, according to IDF and $38.1 \%$ ). We conclude that the different criteria according to NCEP ATPIII and IDF (different values of the marginal blood glucose, waist circumference limit, and the assessment of BMI at IDF) do not play in patients with RA a large part and therefore patients with borderline values (according to NCEP ATPIII and to IDF criteria) and with RA are few. Also, we see that the tightening of criteria for MS to better prediction of cardiovascular risk and identify risk individuals is not as important in patients with RA as in the whole population. 


\section{Prevalence of components of metabolic syndrome}

The most frequent component of MS in patient with RA in all age groups was central obesity. We observed a number of paradoxes. One is the low prevalence of low HDL levels in patients with RA in older age groups compared with the control population. In part this may be due to the effect of GC. The average level of HDL in patients with RA treated with GC was $1.57 \mathrm{mmol} / 1$, but in patients not treated with GC only $1.39 \mathrm{mmol} / 1$. Similar results were published by García-Gómez et al. from University Hospital in Barcelona (12); and Boers et al., who confirmed low levels of HDL in the early stages of RA and a significant increase in HDL levels after treatment (13).

Another paradox is glycemia. The prevalence of hyperglycemia (according to NCEP ATPIII criteria) was in patients with RA in the age groups up to 59 years comparable to the control group, but in the age group over 60 is growing dramatically (39.5\% in RA versus $25.0 \%$ control group, $\mathrm{p}<0.01$ ). This fact can not be attributed to the effect of GC, whereas in the group of patients in 59 years used the GC even more patients than in the group over 60 years $(32.7 \%$ versus $26.3 \%$, p <0.01).

Effect of inflammatory activity on the prevalence of metabolic syndrome

It was important to examine the impact of inflammatory activity in MS prevalence and thus indirectly influence of aggressive medical management. We confirmed the assumption (14) (10) - patients with increased inflammatory activity (defined by level of CRP $5 \mathrm{mg} / \mathrm{l}$ and more) have a higher prevalence of metabolic syndrome. Interestingly, in patients with normal inflammatory activity (defined by levels of CRP $5 \mathrm{mg} / \mathrm{l}$ ), the prevalence of MS according to various criteria was very similar, but in patients with higher inflammatory activity with tightness criteria increased.

Almost all components of the metabolic syndrome were more frequent in patients with higher inflammatory activity ( $p<0.01$ ), except for the prevalence of low HDL $30.9 \%$ versus $31.8 \%, p=0.97$ ). In the pathogenesis of acute and chronic inflammation plays an important role phospholipase A2 (15), which level in the sites of inflammation and in plasma grow. One of the pleiotropic effects is a reduction in HDL cholesterol (16). If we compare the levels of HDL cholesterol, HDL cholesterol is lower in patients with increased inflammatory activity (although not significantly) ( $1.46 \pm 0.42 \mathrm{mmol} / 1$ versus $1.43 \pm 0.34 \mathrm{mmol} / \mathrm{l}, \mathrm{p}=0.4)$. If we turn our attention to a compare groups receiving the same treatment (e.g. methotrexate), the differences are more pronounced and statistical significance increases (1.73 \pm 0.44 $\mathrm{mmol} / 1$ versus $1.59 \pm 0.28 \mathrm{mmol} / \mathrm{l}, \mathrm{p}=0.19$ ).

\section{The effect of treatment on the prevalence of metabolic syndrome}

Prevalence of metabolic syndrome was low in patients treated with modern aggressive treatment (such as methotrexate or leflunomide), in patients treated with methotrexate was even significantly lower than in the same age group in the Slovak population. Patients taking other drugs had a similar prevalence of MS, respectively higher than the control group.

In 2009, Toms et al. examined the prevalence of MS in 400 patients with RA. This study confirmed the prevalence of MS in $45.3 \%$ of patients with RA according to IDF criteria (48.3\% according to IDF in our series). In patients receiving methotrexate, the prevalence was significantly lower than in other treatments (17).

We see that the prevalence of MS in populations with different treatment varies, ranging from values lower than in the control population, to higher values. Thus, when publishing the results of the prevalence of MS in different studies it is necessary to specify the composition of the file according to treatment.

\section{Effect of corticosteroids use on the prevalence of metabolic syndrome}

In our work we have not confirmed the assumption that the patient treated with GC have higher prevalence of MS. When comparing all patients, patients treated with GC had a lower prevalence of MS (by NCEP ATPIII 38.5\% versus 47.5\%, p <0.01). In assessing the prevalence in patients treated with methotrexate - patients treated with combination of methotrexate and GC had the prevalence of MS significantly higher than others (according to NCEP ATPIII 33.3\% versus 25\%, p <0.01). 
It seems that when we used GC in the treatment alone or with drugs with a weaker effect - anti-inflammatory effect is greater than the adverse effects (in terms of central obesity) and the overall prevalence of MS is lower. However, when we used GC as a complementary therapy to aggressive treatment - dual anti-inflammatory therapy is not as significant to outweight adverse effects in terms of central obesity and overall prevalence of MS is higher.

\section{Effect of methotrexate therapy on the prevalence of metabolic syndrome}

The next logical step was to analyze which parameters of MS are in patients with RA treated with methotrexate positively or negatively affected. In comparison with all patients there was significantly reduced the frequency of elevated levels of TAG (25\% versus $47.4 \%, \mathrm{p}$ $<0.01)$, low HDL (7.1\% versus $31.6 \%$, p <0.01) and hyperglycemia $(14.3 \%$ versus $39.5 \%$ according to NCEP ATPIII criteria, $\mathrm{p}<0.01$ ). The frequency of elevated blood pressure was also reduced, but not significantly $(\mathrm{p}=0.75)$. There was no difference in the prevalence of central obesity.

\section{Study strengths and limitations}

One of the limitations of the study should be small sample size, but this is outweighed by using a more stringent statistical criteria for significance $(\mathrm{p}<0.01)$. Other limitation appears to be a sex of the sample group $(95,4 \%$ women). But also in the control groups were more women and the prevalence of MS in higher age groups were similar between men and women (little bit higher in men). Otherwise, if we find significant differences in comparing groups with more women and with nearly all women, differences between the same sex groups will be bigger.

\section{CONCLUSION}

The prevalence of MS in patients with RA is significantly higher than in the Slovak population. This is partly due to differences in average age in both groups. When comparing the prevalence of the same age group - differences are not as pronounced but still significant.

The prevalence of MS in patients with RA depends (in addition to age) on treatment. Patients treated with modern aggressive treatment such as methotrexate or leflunomide have a lower prevalence of MS, patients receiving methotrexate, even lower than the control population.

Similarly, patients with low inflammatory activity (evaluated by level of C-reactive protein) have a significantly lower prevalence of MS. Patients with low inflammatory activity compared to patients with higher inflammatory activity have lower prevalence of almost all components of MS (except for low HDL levels).

These data point to a chronic inflammation as a key copartner of metabolic syndrome and accelerated atherosclerosis. Aggressive treatment of underlying disease, associated with the reduction of inflammatory burden, could reduce cardiovascular morbidity and mortality.

\section{REFERENCES}

1. Breitrose, PE. History (of the Stanford Prevention Research Center). [Online] Stanford Prevention Research Center. [Dátum: 1. FEB 2011.] http://prevention.stanford.edu/about/history.html.

2. Chung, CP; Avalos, I; Oeser, A; Gebretsadik, T; Shintani, A; Raggi, P; Michael Stein, C. High prevalence of the metabolic syndrome in patients with systemic lupus erythematosus: association with disease characteristics and cardiovascular risk factors. Ann Rheum Dis. 2007, 66, 208-214 pp.

3. Chung, CP; Oeser, A; Solus, JF; Avalos, I; Gebretsadik, T; Shintani, A; Raggi, P; Sokka, T; Pincus, T; Stein, CM. Prevalence of the metabolic syndrome is increased in rheumatoid arthritis and is associated with coronary atherosclerosis. Atherosclerosis. 2008, 196, 756-763 pp. 
4. Crowson, CS; Myasoedova, E; Davis, JM; Matteson, EL; Roger, VL; Therneau, TM; Fitz-Gibbon, P; Rodeheffer, RJ; Gabriel, SE. Increased Prevalence of Metabolic Syndrome Associated with Rheumatoid Arthritis in Patients without Clinical Cardiovascular Disease. J Rheumatol. 2011, 38(1), 29-35 pp.

5. Karvounaris, SA; Sidiropoulos, PI; Papadakis, JA; Spanakis, EK; Bertsias, GK; Kritikos, HD; Ganotakis, ES; Boumpas, DT. Metabolic syndrome is common among middle-to-older aged Mediterranean patients with rheumatoid arthritis and correlates with disease activity: a retrospective, cross-sectional, controlled, study. Ann Rheum Dis. 2007, 66, 28-33 pp.

6. Love, TH; Qureshi, AA; Wood Karlson, E; Gelfand, JM; Choi, HK. Prevalence of the Metabolic Syndrome in Psoriasis - Results From the National Health and Nutrition Examination Survey, 2003-2006. Arch Dermatol. 2011, 147(4), 419-424 pp.

7. Papadakis, JA; Sidiropoulos, PI; Karvounaris, SA; Vrentzos, GE; Spanakis, EK; Ganotakis, ES. High prevalence of metabolic syndrome and cardiovascular risk factors in men with ankylosing spondylitis on anti-TNFalpha treatment: correlation with disease activity. Clinical and experimental rheumatology. 2009, 27(2), 292-298 pp.

8. Sommer, D; Jenisch, S; Suchan, M; Christophers, E; Weichenthal, M. Increased prevalence of the metabolic syndrome in patients with moderate to severe psoriasis. Archives of Dermatological Research. 2007, 298, pp. 321-328.

9. Raychaudhuri, SK; Chatterjee, S; Nguyen, C; Kaur, M; Jialal, I; Raychaudhuri, SP. Increased Prevalence of the Metabolic Syndrome in Patients with Psoriatic Arthritis. Metabolic Syndrome and Related Disorders. 2010, 8(4), pp. 331-334.

10. Ridker, PM; Uring, JE; Cook, NR. C-reactive protein, the metabolic syndrome, and the risk of incident of cardiovascular events. Circulation. 2003, 107, 391 - 397 pp.

11. Malesci, D; Niglio, A; Mennillo, GA; Buono, R; Valentini, G; La Montagna, G. High prevalence of metabolic syndrome in patients with ankylosing spondylitis. Clin Rheumatol. 2007, 26, 710-714 pp.

12. García-Gómez, C; Nolla, JM; Valverde, J; Narváez, J; Corbella, E; Pintó, X. High HDL-cholesterol in women with rheumatoid arthritis on low-dose glucocorticoid therapy. Eur J Clin Invest. 2008, 38(9), 686-692 pp.

13. Boers, M; Nurmohamed, MT; Doelman, CJ; Lard, LR; Verhoeven, AC; Voskuyl, AE; Huizinga, TW; van de Stadt, RJ; Dijkmans, BA; van der Linden, S. Influence of glucocorticoids and disease activity on total and high density lipoprotein cholesterol in patients with rheumatoid arthritis. Ann Rheum Dis. 2003, 62(9), pp. 842-845.

14. Yudkin, JS; Stehouwer, CD; Emeis, JJ; Coppack, SW. C-reactive protein in healthy subjects: associations with obesity, insulin resistance, and endothelial dysfunction: a potential role for cytokines originating from adipose tissue? Arterioscler Thromb Vasc Biol. 1999, 19, 972 - 978 pp.

15. Nevalainen, TJ; Haapamäki, MM; Grönroos, JM. Roles of secretory phospholipases A(2) in inflammatory diseases and trauma. Biochimica et Biophysica Acta. 2000, 1488, pp. 83-90.

16. Tietge, UJF; Maugeais, C; Lund-Katz, S; Grass, D; DeBeer, FC; Rader, FDJ. Human Secretory Phospholipase A2 Mediates Decreased Plasma Levels of HDL Cholesterol and ApoA-I in Response to Inflammation in Human ApoA-I Transgenic Mice. Arteriosclerosis, Thrombosis, and Vascular Biology. 2002, 22, pp. 1213-1218.

17. Toms, TE; Panoulas, VF; Holly, J; Douglas, KMJ; Kitas, GD. Methotrexate therapy associates with reduced prevalence of the metabolic syndrome in rheumatoid arthritis patients over the age of 60 - more than just an antiinflammatory effect? A cross sectional study. Arthritis Research \& Therapy. 2009, R110, 1-10 pp.

18. Galajda, P; Mokáň, M; Prídavková, D; Tomášková, V; Šutarík, L; Kručinská, L; Bukovská, A; Rusnáková, G. Prevalencia metabolického syndrómu na Slovensku. Interná medicína. 2007, 6, 325-331 pp.

19. Galajda, P. Prevalencia metabolického syndrómu na Slovensku. Kazuistiky v diabetologii. 2006, 2, 41-42 pp.

\section{Acknowledgement}

This work was partially supported by Commenius University grant N.289/2011 and grant VEGA 1/0005/08.

Received: July, 7, 2012

Accepted: October, 15, 2012 